\title{
DESIGN AND STATISTICAL OPTIMIZATION OF MOUTH DISSOLVING SUBLINGUAL FILM OF FIXED DOSE COMBINATION OF DOXYLAMINE SUCCINATE AND PYRIDOXINE HYDROCHLORIDE USING DESIGN OF EXPERIMENT IN THE TREATMENT OF NAUSEA AND VOMITING IN PREGNANCY
}

\author{
BOBDE SUWARNA SURESH ${ }^{1,2 *}$, TANK HEMRAJ M ${ }^{3}$ \\ ${ }^{1}$ Department of Pharmaceutics, P.E.S's Rajaram and Tarabai Bandekar College of Pharmacy, Ponda, Goa, India, ${ }^{2}$ Department of \\ Pharmaceutics, School of Pharmacy, RK University Rajkot, Rajkot, Gujarat, India. ${ }^{3}$ Department of Pharmaceutics, Atmiya Institute of \\ Pharmacy, Rajkot, Gujarat, India. Email: suwarnabobde@gmail.com
}

Received: 16 April 2018, Revised and Accepted: 27 July 2018

ABSTRACT

Objective: The present research aims at formulating a mouth dissolving sublingual film of fixed dose combination of doxylamine succinate (DS) and pyridoxine hydrochloride (PH) that would provide faster onset of action and hence relief from the condition of nausea and vomiting in pregnancy.

Methods: Mouth dissolving films were prepared using a solvent casting technique. A $2^{3}$ full-factorial design of eight formulations was set up with three independent variables: X1 - polymer 1 HPMC E15 concentration, X2 - polymer 2 HPMC E5 concentration, and X3 - plasticizer PEG 400 concentration. The responses, i.e., dependent variables measured for the study were Y1 disintegration time in seconds, $Y 2$ tensile strength in $\mathrm{kg} / \mathrm{cm}^{2}, Y 3 \mathrm{drug}$ release in the percentage of DS, and Y4 drug release in the percentage of PH. All the formulations were evaluated for physicochemical parameters such as clarity, weight, thickness, folding endurance, surface $\mathrm{pH}$, and content. The design expert software 11.0 trial version was used for statistical analysis of the responses.

Results and Conclusion: All the film formulations were found to be transparent, non-tacky, and easily peelable having the satisfactory tensile strength and folding endurance. The concentration of polymer 1 and 2 was found to have a significant effect on disintegration time and drug release of mouth dissolving films. The best film formulation DP1 was found to have a disintegration time of $77.66 \mathrm{~s}$ and found to release $96.22 \%$ of DS and $95.43 \%$ of pyridoxine $\mathrm{HCl}$ in $21 \mathrm{~min}$.

Keywords: Sublingual film, Mouth dissolving film, Doxylamine succinate, Pyridoxine hydrochloride.

(c) 2018 The Authors. Published by Innovare Academic Sciences Pvt Ltd. This is an open access article under the CC BY license (http://creativecommons. org/licenses/by/4. 0/) DOI: http://dx.doi.org/10.22159/ajpcr.2018.v11i12.27978

\section{INTRODUCTION}

Nausea, a feeling of impending vomiting, is common in pregnancy [1]. Around $70-80 \%$ of the women, during their first trimester in pregnancy, suffer from nausea and vomiting. Nausea and vomiting in pregnancy (NVP) can be mild to moderate. Severe NVP may indicate a condition of hyperemesis gravidarum [2]. Hyperemesis gravidarum is characterized by persistent vomiting, dehydration, ketonuria, electrolyte abnormalities (hypokalemia), and weight loss of more than $5 \%$. This deteriorates the pregnant woman's quality of life [3]. The American College of Obstetricians and Gynecologists recommend the administration of pyridoxine hydrochloride (PH) or combination with doxylamine succinate (DS) for the prevention and treatment of NVP [4]. This combination of PH (Vitamin B6) and DS is given as first-line treatment as it is found to be safe and effective. Antiemetic drugs, $\mathrm{PH}$, is chemically 5-hydroxy-6-methyl-3,4pyridinedimethanol hydrochloride (Fig. 1) and DS is N,N-dimethyl-2[1phenyl-1-(2-pyridinyl) ethoxy]-butanedioate (Fig. 2) [4].

Antiemetic drugs, DS and PH, are a synergistic combination available in the market as a delayed release tablet. The drugs are released and absorbed in the intestine, which results in delay in the onset of action, and as such, the pregnant women are required to take this medication at night so that morning sickness can be prevented. There is a need to provide faster onset of action to pregnant women who require relief from this condition. Sublingual route is rich in blood supply, and the absorption is $3-10$ times greater than conventional oral route. It bypasses hepatic metabolism and provides for drug absorption directly in the systemic circulation [5]. The present study attempts to exploit the advantages of sublingual route by the administration of DS and PH in the form of sublingual film that would provide faster bioavailability and onset of action and use of the film only if the symptom of nausea exists.

\section{METHODS}

DS was obtained as a gift sample from Indoco Remedies, Verna, Goa. PH was obtained as a gift sample from Merck India Ltd., Usgao Tisk Goa. HPMC E15, E5, and E3 were provided as a gift sample from Colorcon Asia Pvt. Ltd., Verna, Goa. Ascorbic acid was purchased from Avra synthesis Pvt. Ltd., and sucralose was obtained as gift sample from J K Sucralose. PEG 400 was purchased from Hi-Media Pvt., Ltd. Citric acid and raspberry syrup were purchased from SD Fine Chemicals. Distilled water prepared using in-house plant was used for the research work.

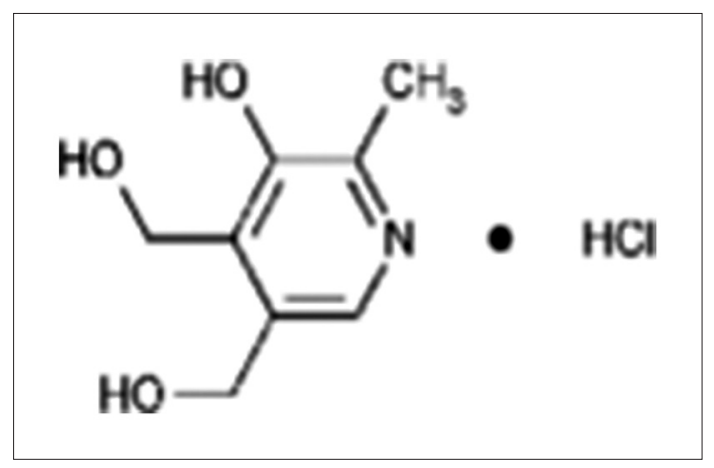

Fig. 1: Pyridoxine hydrochloride 


\section{Analysis of drug}

Simultaneous equation method was used in the estimation of drugs DS and PH. $10 \mathrm{ppm}$ solution of both the drugs was prepared in simulated salivary fluid (SSF), and their spectra were recorded using ultraviolet (UV) spectrophotometer (UV 1800 Shimadzu). From the overlay spectra, the wavelength selected for estimation was the absorption maxima of both the drugs $260.6 \mathrm{~nm}$ and $324 \mathrm{~nm}$, respectively, for DS and PH. The equations used are as given follows:

$$
\begin{gathered}
C x=\frac{(\mathrm{A} 2 \mathrm{ay} 1-\mathrm{A} 1 \mathrm{ay} 2)}{(\operatorname{ax} 2 \mathrm{ay} 1-\mathrm{ax} 1 \mathrm{ay} 2)} \text { and } \\
\mathrm{C}_{\mathrm{Y}}=\frac{(\mathrm{A} 1 \mathrm{ax} 2-\mathrm{A} 2 \mathrm{ax} 1)}{(\mathrm{ax} 2 \mathrm{ay} 1-\mathrm{ax} 1 \mathrm{ay} 2)}
\end{gathered}
$$

$\mathrm{CX}=$ concentration of DS A1 = absorbance of samples at $260.6 \mathrm{~nm}$ $\mathrm{ax} 1=$ absorptivity of DS at $260.6 \mathrm{~nm}$ and ax2 = absorptivity of DS at $324 \mathrm{~nm} \mathrm{CY}=$ concentration of PH A2 = absorbance of samples at $324.0 \mathrm{~nm}$ ay $1=$ absorptivity of $\mathrm{PH}$ at $260.6 \mathrm{~nm}$ and ay $2=$ absorptivity of PH at $324 \mathrm{~nm}$.

\section{Preliminary screening of polymers and plasticizers}

Experimental trials were carried out to find the film-forming capacity of various HPMC polymers, namely E15, E6, E5, and E3. The polymer HMPC E15 gave good films in the concentration range between 3 and $7 \%$, while E3, E6, and E5 gave at above 5\%. The results of the placebo batches indicated HPMC E15 and E5 used in combination gave good transparent, non-tacky films of adequate stiffness with PEG 400 as plasticizer. Preliminary trials were carried out for the selection of plasticizer from PEG 400, glycerine, and propylene glycol. Glycerine produced tacky films while propylene glycol films were not easy to peel. PEG 400 when used produced easily peelable non-tacky films and was hence selected for the formulation.

\section{Experiment design}

An experimental design of eight formulations was set up using three factors at two levels. The factors as independent variable chosen were

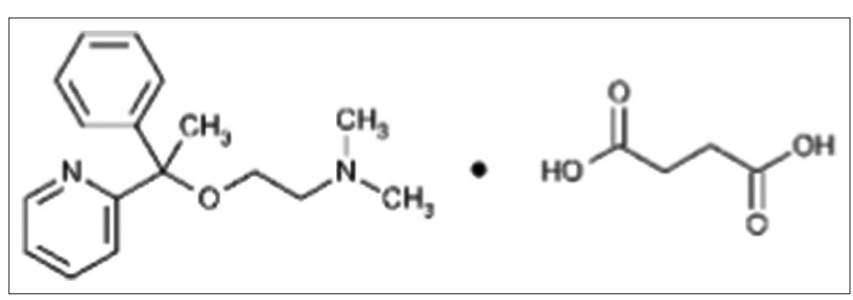

Fig. 2: Doxylamine succinate

\begin{tabular}{|c|c|c|c|c|c|c|c|c|c|c|}
\hline \multirow[t]{2}{*}{ Code } & \multicolumn{3}{|c|}{$\begin{array}{l}\text { Coded } \\
\text { values }\end{array}$} & \multicolumn{3}{|c|}{$\begin{array}{l}\text { Actual values in } \\
\text { percentage (\%) }\end{array}$} & \multicolumn{4}{|c|}{ Dependent variables } \\
\hline & $\mathrm{X} 1$ & $\mathrm{x} 2$ & $\mathrm{X} 3$ & $\mathrm{X} 1$ & $\mathrm{X} 2$ & $\mathrm{X3}$ & Y1 & Y2 & Y3 & Y4 \\
\hline DP1 & -1 & -1 & -1 & 3 & 0.5 & 2 & 77.66 & 77.04 & 96 & 90.26 \\
\hline DP2 & +1 & -1 & -1 & 5 & 0.5 & 2 & 94 & 139.12 & 89 & 84.54 \\
\hline DP3 & -1 & +1 & -1 & 3 & 1 & 2 & 109.33 & 84.07 & 75.75 & 81.91 \\
\hline DP4 & +1 & +1 & -1 & 5 & 1 & 2 & 130 & 141.9 & 68.35 & 59.51 \\
\hline DP5 & -1 & -1 & +1 & 3 & 0.5 & 4 & 100.66 & 43.32 & 97.64 & 94.28 \\
\hline DP6 & +1 & -1 & +1 & 5 & 0.5 & 4 & 165 & 101.53 & 90.21 & 85.27 \\
\hline DP7 & -1 & +1 & +1 & 3 & 1 & 4 & 138.33 & 52.39 & 82.82 & 75.82 \\
\hline DP8 & +1 & +1 & +1 & 5 & 1 & 4 & 174.66 & 108.27 & 78.95 & 69.27 \\
\hline
\end{tabular}

Table 1: Three factor two-level factorial experimental designs

$\mathrm{X} 1$ is \% of HPMC E15 X2 is the \% HPMC E5, X3 is \% of PEG $400 \mathrm{Y} 1$ is

disintegration time in seconds, $\mathrm{Y} 2$ is tensile strength in $\mathrm{kg} / \mathrm{cm}^{2}, \mathrm{Y} 3$ and $\mathrm{Y} 4$ are drug release at $21 \mathrm{~min}$ of $\mathrm{DS}$ and $\mathrm{PH}$, respectively the concentration of HPMC E15 (X1), concentration of HPMC E5 (X2), and concentration of PEG 400 (X3). The responses, disintegration time in seconds (Y1), tensile strength measured in $\mathrm{kg} / \mathrm{cm}^{2}(\mathrm{Y} 2)$, and drug release in percentage (\%) of the drug DS (Y3) and PH (Y4) were chosen as dependant variables. Table 1 gives the layout of the experimental design.

\section{Method of preparing film}

The dose of DS and PH is $10 \mathrm{mg}$ each. The area of 9-cm diameter Petri plate is $63.585 \mathrm{~cm}^{2}$. Amount of drug present in film of $4 \mathrm{~cm}^{2}$ is $10 \mathrm{mg}$, so total amount of each drug to be added to the $10 \mathrm{~mL}$ solution is $63.585 \times 10 / 4=158.96 \mathrm{mg}$.

The polymers were placed overnight for hydration in half the amount of water. Then, the polymer solution was made homogeneous by stirring it using magnetic stirrer (Remi Mumbai). Then, raspberry syrup, sucralose, citric acid, and ascorbic acid were added. Both the drugs were dissolved in water and added to the polymer solution. Once uniform, the formulation was casted on 9-cm diameter Petri plate which was previously lubricated with glycerine. The films were dried in oven at temperature of $38^{\circ} \mathrm{C}$. The films when dried were peeled off using a sharp knife and then cut in $2 \mathrm{~cm} \times 2 \mathrm{~cm}$ size. The films were then wrapped in aluminum foil and stored in desiccators.

\section{Drug excipient compatibility}

The compatibility of the formulation in the solid state was checked using differential scanning calorimetry (DSC) of making Universal V4SA TA Instrument in a nitrogen atmosphere with a heating rate of $1^{\circ} \mathrm{C} / \mathrm{min}$ at a temperature between -100 and $400^{\circ} \mathrm{C}$.

\section{Evaluation}

The prepared films were evaluated for physical appearance, weight, thickness surface $\mathrm{pH}$, disintegration time, drug content, folding endurance, tensile strength, in vitro release, and ex vivo permeation studies. The physical appearance of the film such as homogeneity, color, transparency, and tackiness of the films was checked by visual inspection. Three films were weighed using Sartorius electronic balance (Shimadzu, Japan), and average and standard deviation were calculated. The thicknesses of the three films at three locations per film were determined using micrometer (Mitutoyo, Japan). The average and standard deviation were recorded. Surface $\mathrm{pH}$ was determined by placing a drop of water on the film and determined the $\mathrm{pH}$ by placing an electrode on it [6]. The disintegration time was determined using the disintegration test apparatus IP (Veego Instruments, Mumbai India). For the drug content, the film was dissolved in SSF, and then, dilutions were made and absorbance recorded and drug content was determined using UV spectrophotometer (UV 1800 Shimadzu, Japan) by method developed using simultaneous equation method. Folding endurance was determined by folding the cut films in the same plane until they developed cracks and the times it is folded without causing crack are recorded as folding endurance. Tensile strength was determined using the formula load at fracture multiplied by hundred divided by the product of film thickness and film width. In vitro drug release was determined using a modified dissolution method (Veego Instruments, Mumbai India) as stated in Dinge et al. using $20 \mathrm{~mL}$ of SSF as dissolution medium with speed of $50 \mathrm{rpm}$ and temperature of $37^{\circ} \mathrm{C}$ [7].

\section{Statistical analysis}

The data obtained are analyzed using Design Expert 11.0 Software Trial version from Stat ease Inc. The contribution of each factor and its effect on response is obtained using ANOVA and response surface graphs. The significance level was considered to be $\mathrm{p}<0.05$ [8].

\section{Ex vivo permeation}

The study was carried out for the best-optimized formulation using the excised buccal mucosa of goat using modified Franz diffusion cell. The buccal mucosa of freshly killed goat was obtained from the local slaughterhouse. The mucosa was evenly trimmed and then washed with Ringer's solution. The modified Franz diffusion cell consisted of 
a beaker containing $20 \mathrm{ml}$ of SSF warmed at $37^{\circ} \mathrm{C}$ which served as a receptor compartment. A test tube with $2 \mathrm{~cm}$ diameter was cut to obtain a cylinder which was open on both the ends to which the treated buccal mucosa was attached which acted as a donor compartment. The assembly was placed on a magnetic stirrer (Remi make). The film was placed on the inner side of the buccal mucosa which was mounted between the donor and receptor compartment. To the donor compartment containing the film, $1 \mathrm{~mL}$ of SSF was added. The receptor medium was stirred using magnetic bead. Samples of $2 \mathrm{~mL}$ were withdrawn at 3, 6, 9, 12, 15, 18, 21, and 24 min and replaced with 2-ml SSF at each time point. The absorbance was measured at $260.6 \mathrm{~nm}$ and $324 \mathrm{~nm}$, and the drug permeation across the buccal mucosa was estimated using simultaneous equation method [8].

Stability study was done on the optimized formulation. The films were wrapped in aluminum foil and stored at room temperature and $40^{\circ} \mathrm{C} \pm 2{ }^{\circ} \mathrm{C}$ and $75 \% \pm 5 \% \mathrm{RH}$ for 3 months. They were evaluated for appearance, weight, thickness, folding endurance, disintegration time, drug content, and drug release.

\section{RESULTS AND DISCUSSION}

Method for the estimation of drugs

The wavelength selected for simultaneous equation method is as shown in Fig. 3.

- Two simultaneous equations using absorptivity coefficients were formed as follows:

- $\mathrm{A}_{1}=00.00956 \mathrm{C}_{1}+0.00015 \mathrm{C}_{2}$

- $\mathrm{A}_{2}=0.01545 \mathrm{C}_{1}+0.0352 \mathrm{C}_{2}$, where $\mathrm{A}_{1}$ and $\mathrm{A}_{2}$ are absorbances of solution and $\mathrm{C}_{1}$ and $\mathrm{C}_{2}$ concentrations of $\mathrm{DS}$ and $\mathrm{PH}$ in $\mathrm{mcg} / \mathrm{mL}$. Hence, concentration of the drug can be calculated as follows:

$$
\begin{gathered}
C_{D S}=\frac{A 2(0.01545)-A 1(0.0352)}{-0.0003341} \\
C_{P H}=\frac{A 1(0.00015)-A 2(0.00956)}{-0.0003341}
\end{gathered}
$$

Preliminary trials

Trials carried out of placebo films depict that HPMC E15 produced good peelable films in comparison to HPMC E5 and E3 when used alone but had

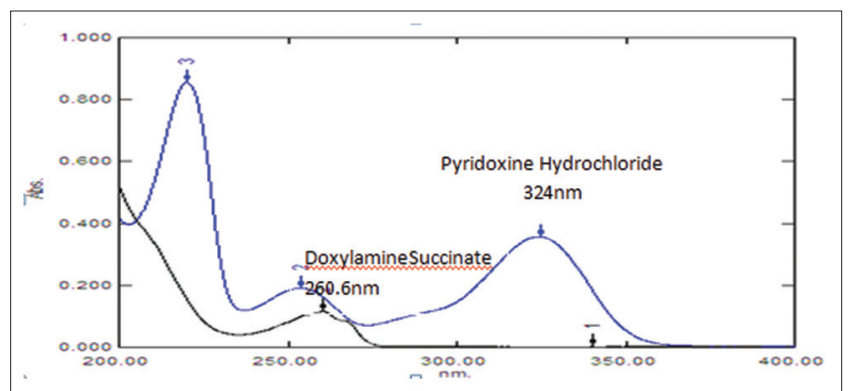

Fig. 3: Overlay spectra of doxylamine succinate and pyridoxine hydrochloride in simulated salivary fluid

Table 2: Preliminary trial of placebo films

\begin{tabular}{llllllllll}
\hline Ingredients & F1 & F2 & F3 & F4 & F5 & F6 & F7 & F8 & F9 \\
\hline HPMC E15 & 3 & - & - & 0.5 & 3 & 3 & 0.5 & 1 & 3 \\
HPMC E5 & - & 3 & - & - & 0.5 & 1 & 3 & 3 & - \\
HPMC E3 & - & - & 3 & 3 & - & - & - & - & 0.5 \\
PEG400 & 2 & 2 & 2 & 2 & 2 & 2 & 2 & 2 & 2 \\
Water & 10 & 10 & 10 & 10 & 10 & 10 & 10 & 10 & 10 \\
Film property & +++ & ++ & + & + & +++ & +++ & ++ & ++ & ++ \\
\hline
\end{tabular}

+++ : Good peelable films with good tensile strength. ++: Peelable films having low tensile strength. + : Films difficult to peel low tensile strength at the lowest concentration of 3\%. Combination of HPMC E15 and E5 with HPMC E15 at high concentration of 3\% and HPMC E5 at low concentration $0.5-1 \%$ gave better results than the reverse combination, respectively. Results of the trials are tabulated in Table 2.

\section{Optimized factorial design}

Based on the trials of placebo batch, the concentration of HPMC E15, E5, and Plasticizer PEG400 at two levels was chosen as factors for experimental design as shown in Table 1.

\section{Drug excipient compatibility}

The DSC spectra of the pure drugs DS, PH combination of drugs DS$\mathrm{PH}$, and combination of both drugs with excipients are as shown in Figs. 4-7, respectively. The spectra of the pure drug DS and PH show sharp endothermic peak at $100.90^{\circ} \mathrm{C}$ and $206.7^{\circ} \mathrm{C}$, respectively. The combination of DS-PH spectra shows a slight shift in endothermic peak of DS at $102.48^{\circ} \mathrm{C}$ and $\mathrm{PH}$ at $210.80^{\circ} \mathrm{C}$. The spectra of a combination of DS-PH and excipients show endothermic peak of DS at $100.27^{\circ} \mathrm{C}$ and $\mathrm{PH}$ at $197.54^{\circ} \mathrm{C}$. The slight shift in the endothermic peak of $\mathrm{PH}$ may be due to change in glass transition temperature of polymers. There is no major change in spectra which rules out the possibility of any drug excipient incompatibility.

\section{Evaluation of films}

The prepared films were evaluated for weight, thickness, folding

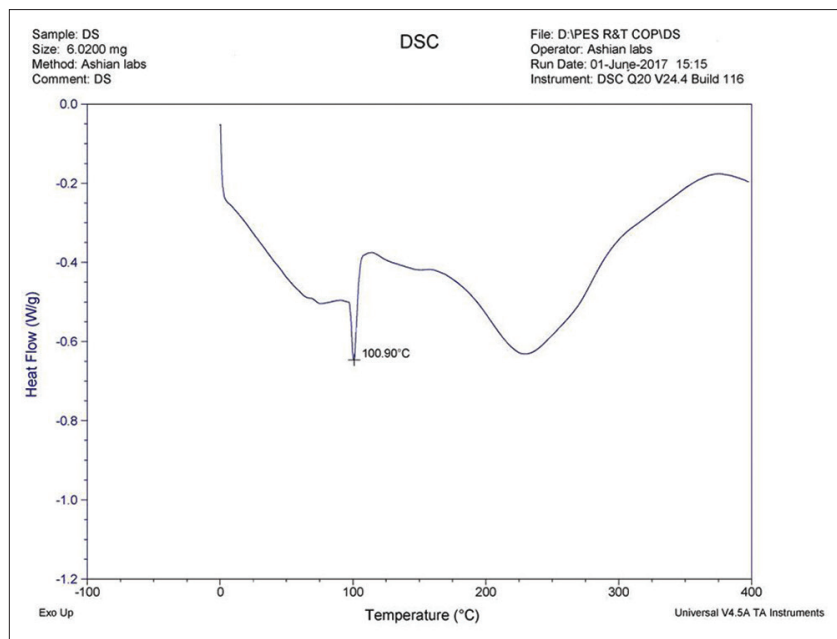

Fig. 4: Differential scanning calorimetry spectra of doxylamine succinate

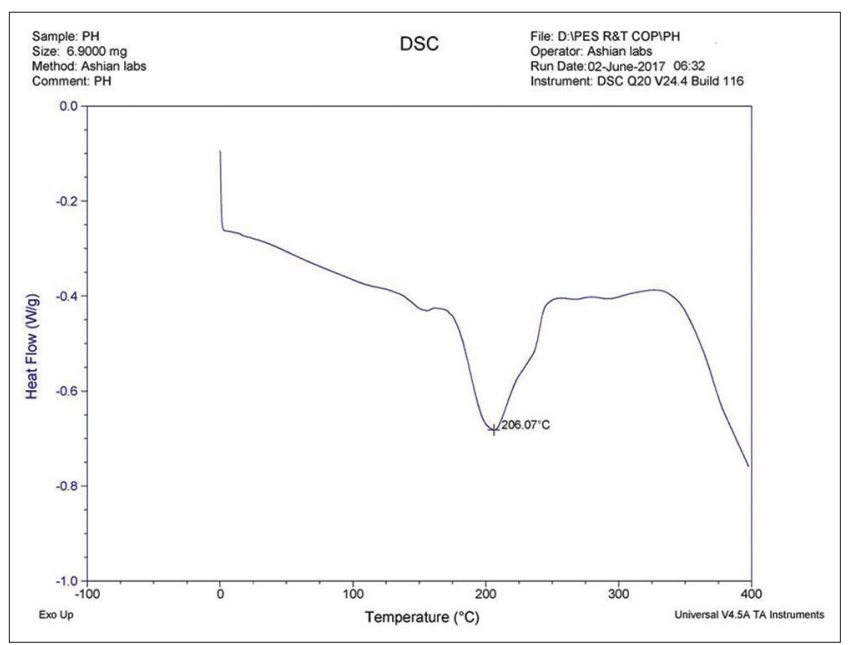

Fig. 5: Differential scanning calorimetry spectra of pyridoxine hydrochloride 
Table 3: Physicochemical evaluation of films

\begin{tabular}{|c|c|c|c|c|c|c|}
\hline Code & Weight (mg) ${ }^{a}$ & Thickness $^{\mathrm{a}}$ (mm) & Folding endurance $^{a}$ & Percent elongation $^{a}$ & Assay (\%) DS & Assay (\%) $\mathrm{PH}^{\mathrm{a}}$ \\
\hline DP1 & $145.66 \pm 3.055$ & $0.246 \pm 0.011$ & $898.0 \pm 3.0$ & $1.25 \pm 0$ & $97.65 \pm 0.963$ & $100.65 \pm 1.035$ \\
\hline DP2 & $161.0 \pm 2.0$ & $0.316 \pm 0.005$ & $932.33 \pm 2.516$ & $3.33 \pm 0.72$ & $98.41 \pm 0.870$ & $99.06 \pm 0.697$ \\
\hline DP3 & $146.0 \pm 3.0$ & $0.25 \pm 0.01$ & $980.0 \pm 2.00$ & $2.5 \pm 1.25$ & $100.95 \pm 2.053$ & $97.49 \pm 0.212$ \\
\hline DP4 & $154.66 \pm 1.527$ & $0.266 \pm 0.005$ & $1053.66 \pm 3.21$ & $3.75 \pm 1.25$ & $98.95 \pm 0.843$ & $98.3 \pm 1.433$ \\
\hline DP5 & $167.03 \pm 1.732$ & $0.29 \pm 0.01$ & $1154.0 \pm 2.0$ & $5 \pm 3.30$ & $97.46 \pm 0.848$ & $98.99 \pm 0.681$ \\
\hline DP6 & $166.33 \pm 2.309$ & $0.306 \pm 0.011$ & $1207.33 \pm 2.516$ & $6.25 \pm 0$ & $100.74 \pm 1.087$ & $97.84 \pm 0.371$ \\
\hline DP7 & $171.66 \pm 1.527$ & $0.29 \pm 0.017$ & $1247.33 \pm 2.516$ & $2.08 \pm 1.44$ & $99.88 \pm 1.147$ & $98.21 \pm 1.232$ \\
\hline
\end{tabular}

${ }^{\mathrm{a}}$ Mean \pm SD $\mathrm{n}=3$

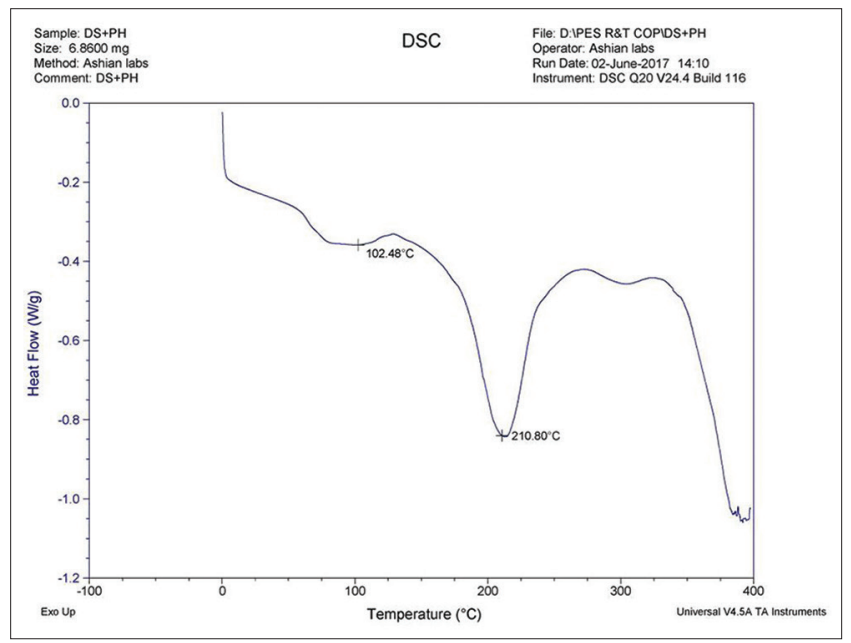

Fig. 6: Differential scanning calorimetry spectra of doxylamine succinate and pyridoxine hydrochloride

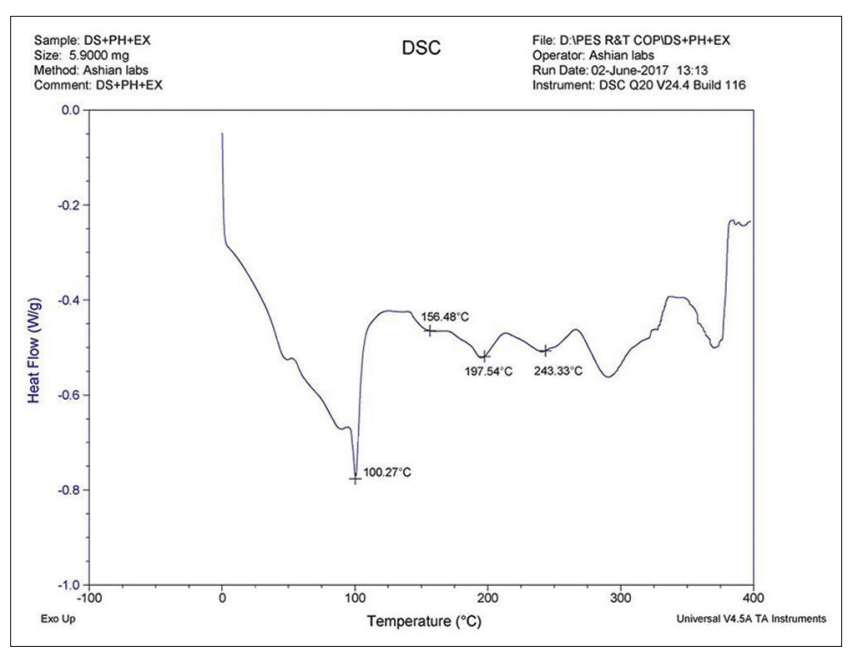

Fig. 7: Differential scanning calorimetry spectra of combination of doxylamine succinate, pyridoxine hydrochloride, and excipients

endurance, percent elongation. and assay of film; the results are tabulated in Table 3. All the mouth dissolving sublingual films were found to be homogenous, transparent, non-tacky, easy to peel, and having adequate tensile strength. The films were found to weigh in the range of $145.66-180 \mathrm{mg}$. The thickness of the films was found to be between $0.246 \mathrm{~mm}$ and $0.326 \mathrm{~mm}$. The folding endurance of all the formulations was found to be very good, i.e., between 898 and 1247, which indicate they are very robust. The percent elongation of the films was found to be in the range of $1.25-6.25 \%$. The drug content in the films was found to be between $97.46 \%$ and $100.99 \%$ for DS and $97.49 \%$ and 100.65 for PH. The surface $\mathrm{pH}$ of the films was found to be between

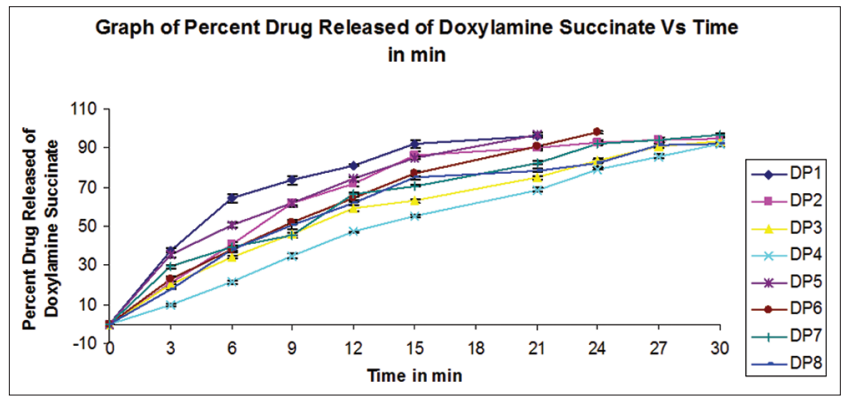

Fig. 8: Drug release of doxylamine succinate from mouth dissolving film formulations DP1-8

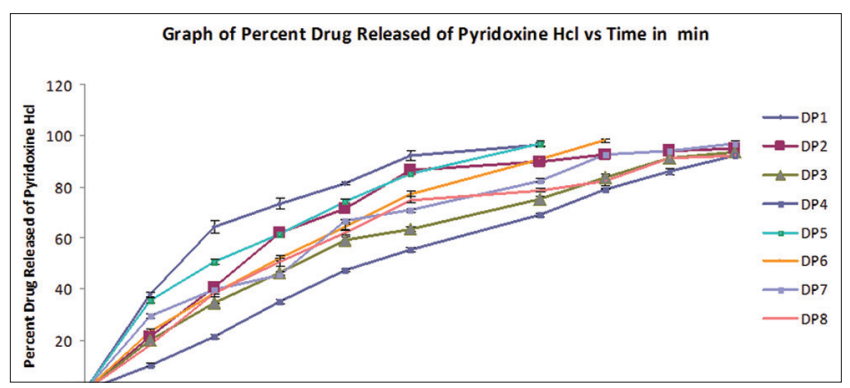

Fig. 9: Drug release of pyridoxine hydrochloride from mouth dissolving film formulations DP1- DP8

6.0 and 6.9. The drug release profile of the film formulations is shown in Figs. 8 and 9 for DS and PH, respectively. The formulation DP1 and DP5 were found to release the drug completely in $21 \mathrm{~min}$ and DP6 in $24 \mathrm{~min}$, while all other formulations showed complete release in $30 \mathrm{~min}$. DP1 and DP5 were found to release around $74-80 \%$ drug in $12 \mathrm{~min}$.

\section{Statistical analysis}

Effect of formulation variables on disintegration time

The polynomial equation generated as per coded factors for response 1 that is disintegration time in second is as given follows:

$\mathrm{Y} 1=+44.3575-6.6625 * \mathrm{X} 1+57.50 * \mathrm{X} 2-10.87250 * \mathrm{X} 3+7.9575 * \mathrm{X} 1 * \mathrm{X} 3$

Where $\mathrm{X} 1$ is a concentration of polymer $1, \mathrm{X} 2$ is a concentration of polymer 2 , and $\mathrm{X} 3$ is concentration of plasticizer. The $\mathrm{p}$ value was found to be 0.0130 which is $<0.05$ (Table 4 ) that indicates that model is significant and the $\mathrm{X} 1, \mathrm{X} 2$, and $\mathrm{X} 3$ were found to be significant model terms as their $p$ value was found to be $<0.05$. The effect of independent variables on disintegration time is shown in response surface plot (Figs. 10 and 11). The disintegration time of the films increased with increase in the concentration of HPMC E15 and E5. The concentration of HPMC E15 was found to have a greater effect than HPMC E5 on disintegration time. Similarly, increase in the concentration of PEG400 and HPMC E15 was found to increase the disintegration time of films. 
Effect of formulation variables on tensile strength

The polynomial equation generated as per coded factors for response 2 that is tensile strength in $\mathrm{kg} / \mathrm{cm}^{2}$ is as given below:

\section{$\mathrm{Y} 2=+18.08+29.25 * \mathrm{X} 1+12.81 * \mathrm{X} 2-17.07750 * \mathrm{X} 3$}

The model for the response was found to be significant as the p value was $<0.05$ (Table 4). The terms X1, X2, and X3 were found to be significant model terms as their $\mathrm{p}$ value was found to be $<0.05$. The effect of independent variables on tensile strength is shown in response surface plot (Figs. 12 and 13). The tensile strength of the films increased with increase in the concentration of HPMC E15 and E5. The concentration of HPMC E15 was found to have greater effect than HPMC E5 on tensile strength. However, increase in the concentration of PEG400 with HPMC E15 was found to decrease the tensile strength of films.

\section{Effect of formulation variables on drug release}

The polynomial equation generated as per coded factors for response 3 [Y3] and 4 [Y4] that is percent drug released for the drug DS and $\mathrm{PH}$, respectively, is as given below:

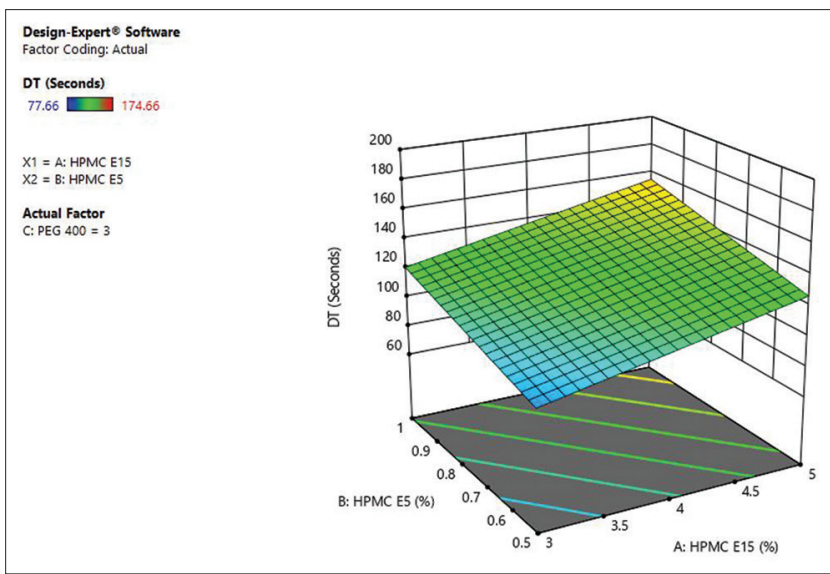

Fig. 10: Response surface plot for the influence of polymer on disintegration time

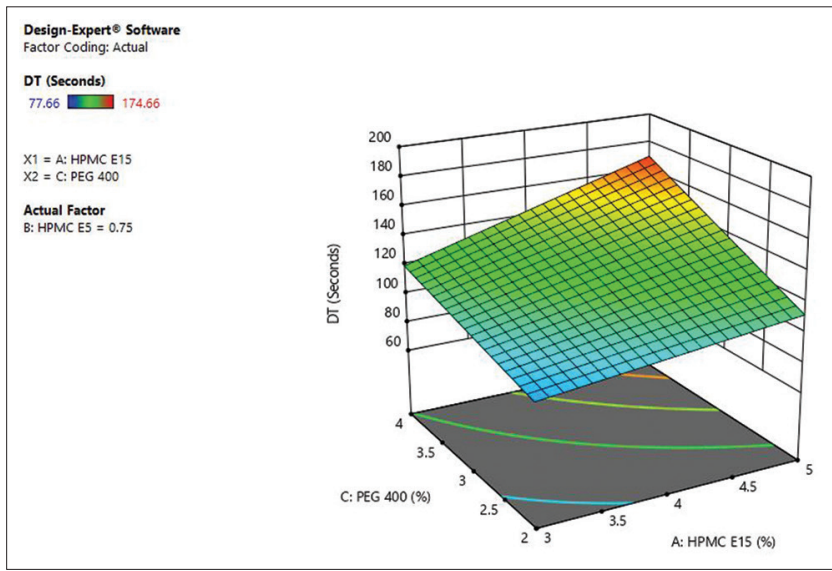

Fig. 11: Response surface plot for the influence of polymer and plasticizer on disintegration time
$\mathrm{Y} 3=+132.885-2.84 * \mathrm{X} 1-58.36 * \mathrm{X} 2-3.61 * \mathrm{X} 3+7.95 * \mathrm{X} 2 * \mathrm{X} 3$

$\mathrm{Y} 4=+131.78750-5.96 * \mathrm{X} 1-35.92 * \mathrm{X} 2$

The model for drug release was found to be significant as the $\mathrm{p}$ value was $<0.05$ (Table 4). The terms X1, X2 X3, and X2*X3 were found to be significant model terms for $\mathrm{Y} 3$ as their $\mathrm{p}$ value was found to be $<0.05$ while for $\mathrm{Y} 4, \mathrm{X} 1$, and $\mathrm{X} 2$ were found to be the significant model terms. In equation $\mathrm{Y} 3, \mathrm{X} 1, \mathrm{X} 2$, and $\mathrm{X} 3$ were found to have an antagonistic effect on drug release as shown by the negative value in the equation -2.84 , 58.36, and -3.61 for $\mathrm{X} 1, \mathrm{X} 2$, and $\mathrm{X} 3$, respectively, while factors $\mathrm{X} 2$ and $\mathrm{X} 3$ in combination were found to have synergistic effect on drug release as shown by positive value +7.95 in the equation [9]. The influence of independent variables on drug release is shown in response surface plot (Figs. 14-17). HPMC is a hydrophilic polymer known for controlling the release of drugs. The drug release of the films decreased with increase in the concentration of HPMC E15 and E5. Increase in concentration of PEG400 with HPMC E15 was found to decrease the release of drug

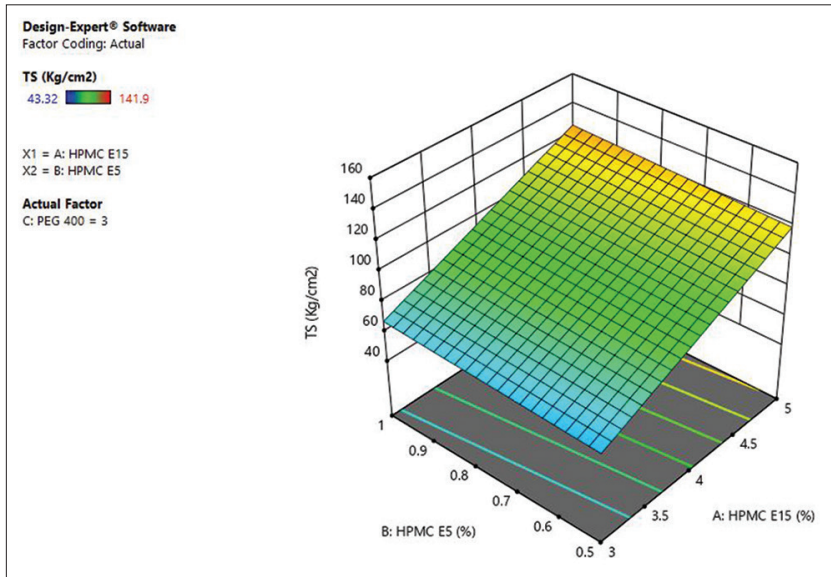

Fig. 12: Response surface plot for the influence of polymer on tensile strength

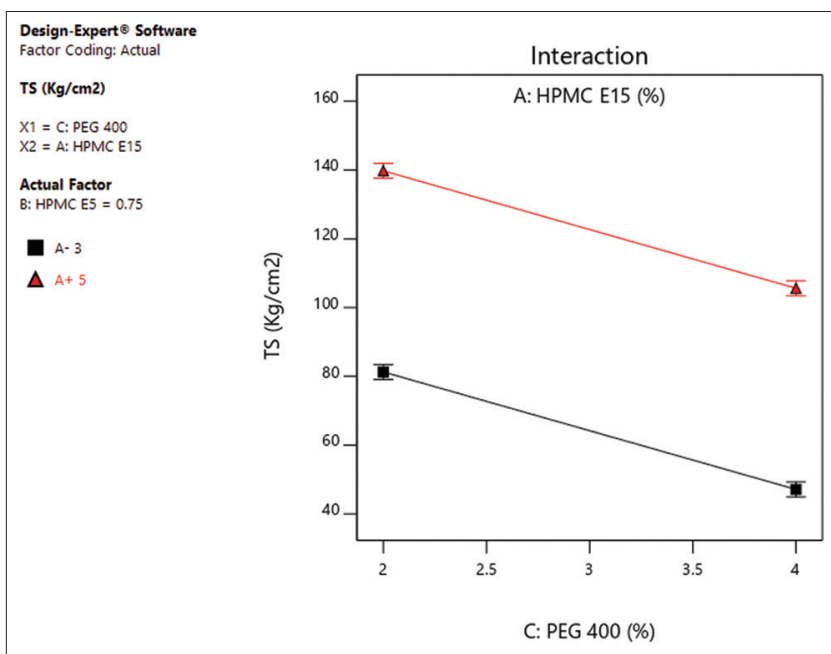

Fig. 13: Interaction plot of effect of plasticizer on tensile strength

Table 4: Model summary statistics of ANOVA analysis

\begin{tabular}{llllllll}
\hline Response & $\mathbf{p}$ value & $\mathbf{R}^{\mathbf{2}}$ & Adjusted $\mathbf{R}^{\mathbf{2}}$ & Predicted $\mathbf{R}^{\mathbf{2}}$ & Adequate precision & SD & CV\% \\
\hline Y1 & 0.0130 & 0.9696 & 0.9290 & 0.7835 & 14.4875 & 7.17 & 7.42 \\
Y2 & 00001 & 0.9984 & 0.9972 & 0.9937 & 73.3102 & 1.91 & 2.04 \\
Y3 & 0.0005 & 0.9967 & 0.9924 & 0.9767 & 38.9447 & 0.8977 & 1.06 \\
Y4 & 0.0019 & 0.9179 & 0.8851 & 0.7899 & 11.9711 & 4.08 & 5.03 \\
\hline
\end{tabular}


from the films. Hence, lower concentration of polymer and plasticizer would form an ideal combination to increase the release of drug from the films.

The statistical data obtained from ANOVA are given in Table 4. The coefficient of variation is $<10 \%$ for all the responses which indicates that the model is reasonably reproducible [10]. The predicted $\mathrm{R}^{2}$ value was found to be in reasonable agreement with adjusted $\mathrm{R}^{2}$, i.e., $<2$ for all the responses that explain the reliability of the model [11]. All the responses in this study show adequate precision value $>4$ which indicates adequate signal, and hence, the model is significant [10].

\section{Optimization}

Design expert software provides an option for the optimization of formulation by choosing a desired goal for each factor and response. The goal for the present study was to have minimum disintegration time and maximum drug release with an optimum tensile strength within a range for the mouth dissolving sublingual film. Based on the

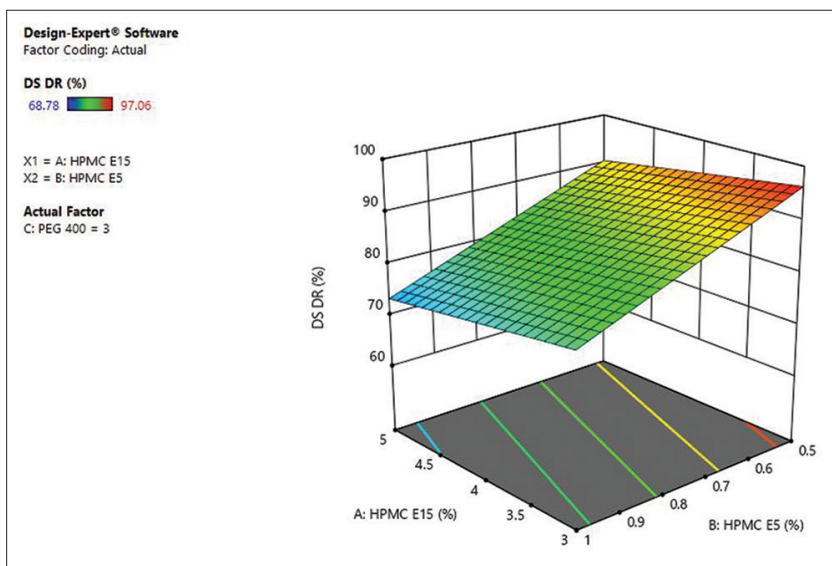

Fig. 14: Response surface plot for the influence of polymer on drug release of DS

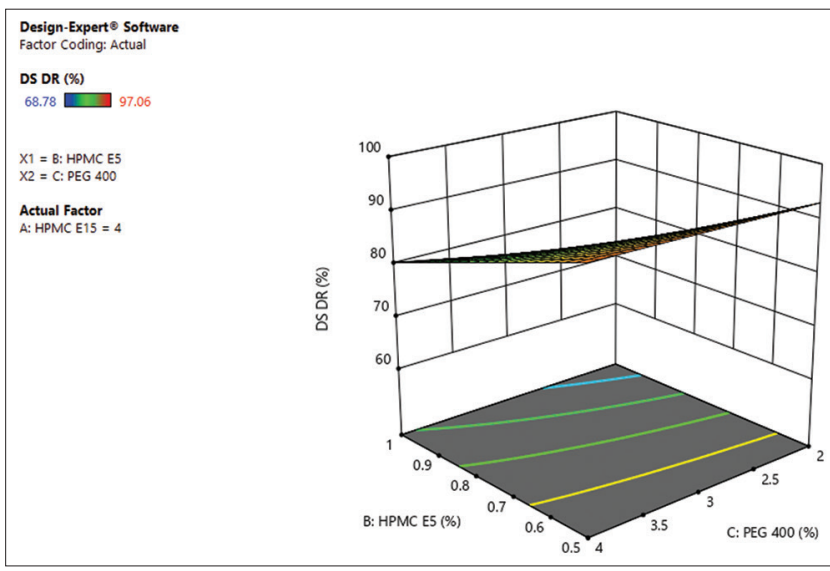

Fig. 15: Response surface plot for the influence of polymer and plasticizer on drug release of DS goals set for the responses, the software provided various solutions having desirability between zero and one. From the various solutions provided based on the response, one solution provided by software was of formulation DP1 having the desirability of 0.981 , which would give a disintegration time of $79.12 \mathrm{~s}$, tensile strength of $78.08 \mathrm{~kg} / \mathrm{cm}^{2}$, and drug release of $95.915 \%$ for DS and $95.947 \%$ for PH. Hence, it was chosen and it provided results similar to that predicted by the software thatbest-optimized formulation would give, fulfilling all the goals.

Ex vivo permeation study of the optimized film formulation DP1 was carried out the results of which are demonstrated in Fig. 17. The films showed more than $80 \%$ drug permeation in time period of $15 \mathrm{~min}$.

\section{Stability test}

The optimized formulation did not show any visual change in appearance and the results of all the tests conducted are tabulated in Table 5 which were found to be within limits which indicates the stability of the formulation.

\section{CONCLUSION}

In the present study, the use of design of experiment has helped to identify the influence of formulation variables on the performance

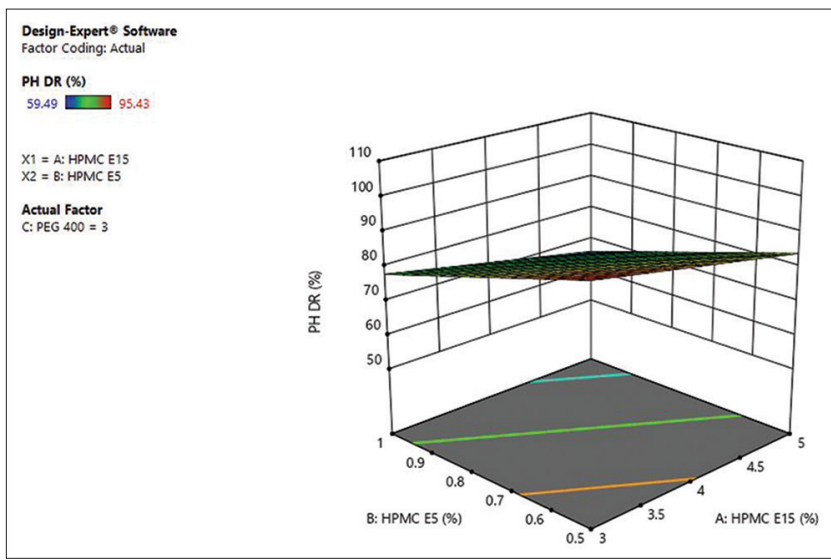

Fig. 16: Response surface plot for the influence of polymer on drug release of $\mathrm{PH}$

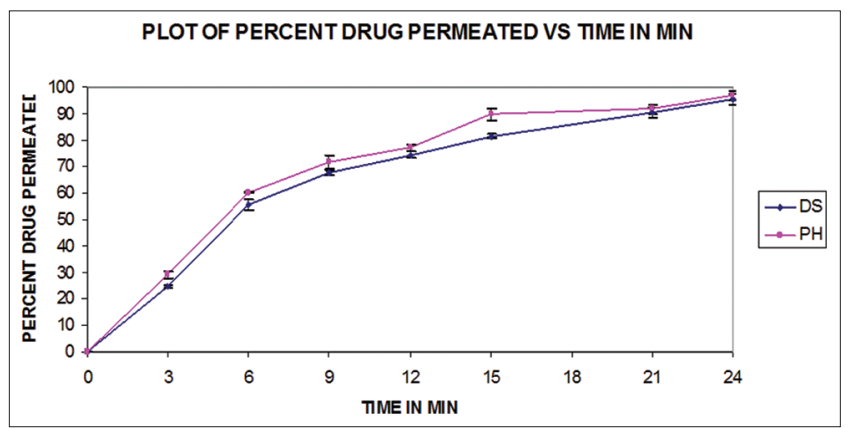

Fig. 17: Ex vivo drug permeation

Table 5: Stability test results of optimized batch

\begin{tabular}{lll}
\hline Testing & Room temperature ambient humidity & 40 $\mathbf{C}$ and $\mathbf{7 5 \%}$ RH \\
\hline Description & Transparent, non-tacky films & Transparent, non-tacky films \\
Folding endurance & $900 \pm 3.5$ & $896 \pm 2.0$ \\
Disintegration time $(\mathrm{s})$ & $72.56 \pm 2.61$ & $75.0 \pm 1.92$ \\
Tensile strength $\left(\mathrm{kg} / \mathrm{cm}^{2}\right)$ & $77.46 \pm 1.02$ & $78.02 \pm 1.76$ \\
Drug release $(\%)$ of DS & $97.21 \pm 1.59$ & $98.33 \pm 1.87$ \\
Drug release $(\%)$ of $\mathrm{PH}$ & $99.09 \pm 2.81$ & $96.20 \pm 0.71$ \\
\hline
\end{tabular}


of mouth dissolving film. The prepared films were found to be homogenous, non-tacky, transparent, and easy to peel. Formulation variables and concentration of HPMC E15 and HPMC E5 were found to influence the disintegration time, tensile strength, and drug release from films. DP1 was found to be the best formulation having disintegration time of $77.66 \mathrm{~s}$, tensile strength of $77.04 \mathrm{~kg} / \mathrm{cm}^{2}$, and providing the drug release of $96.00 \%$ DS and $90.26 \%$ pyridoxine $\mathrm{HCl}$. Mouth dissolving sublingual film of DS and pyridoxine $\mathrm{HCl}$ can be an effective alternative to provide rapid action and relief from NVP to already distressed pregnant women.

\section{ACKNOWLEDGMENT}

The authors would like to thank Dr. S. N. Mamle Desai, Principal of P.E.S's Rajaram and Tarabai Bandekar College of Pharmacy for providing research facility and for his support whenever required and our guide Dr. H. M Tank for his guidance and support.

\section{AUTHORS' CONTRIBUTION}

Miss Suwarna S Bobde is the author for this publication. She is a Research Scholar at School of Pharmacy, R K University, Rajkot, Gujarat, and is currently working as Assistant Professor in the Department of Pharmaceutics at P.E.S's Rajaram and Tarabai Bandekar College of Pharmacy, Farmagudi, Ponda, Goa, where she has carried out all the research work under the guidance of Dr. H M Tank, Principal, Atmiya Institute of Pharmacy, Rajkot, Gujarat.

\section{CONFLICTS OF INTEREST}

All the authors have none to declare.

\section{REFERENCES}

1. Barbara JP. Physiology and pharmacology of nausea and vomiting. Anaesth Intensive care Med 2012;13:598-602.

2. Lee NM, Saha S. Nausea and vomiting of pregnancy. Gastroenterol Clin North Am 2011;40:309-34, 7.

3. Yeh CC. Hyperemesis gravidarum. J Chin Med Assoc 2017;80:526e7.

4. Nayak SC, Kulkarni PV, Bhaskar V, Chavhan V. Development and validation of UV spectrophotometric method for simultaneous estimation of doxylamine succinate and pyridoxine hydrochloride in bulk and tablet dosage form. Int J Pharm Pharm Sci 2013;5:390-3.

5. Patel NK, Panchol SS. An overview on: Sublingual route for systemic drug delivery. Int J Resn Pharm Biomed Sci 2012;3:913-23.

6. Vijaya KS, Rohini P, Reddy KG. Montelukast sodium oral thin films: Formulation and In vitro evaluation. Asian J Pharm Clin Res 2012;5:266-70.

7. Dinge A, Nagarsenker M. Formulation and evaluation of fast dissolving films for delivery of triclosan to the oral cavity. AAPS Pharm Sci Tech 2008;9:349-56.

8. Chaudhary H, Gauri S, Rathee P, Kumar V. Development and optimization of fast dissolving ORO-dispersible films of granisetron Hcl using box Behnken statistical design. Bull Fac Pharm Cairo Univ 2013;51:193-201.

9. Daud A, Peepliwali A, Bonde M, Sapkal N, Gaikwad N. Design and development of Nicotiana tabacum film using factorial design. Int J Pharm Pharm Sci 2016;8:115-23.

10. Jivani RR, Patel CN, Jivani NP. Statistical design of experiments on fabrication of bilayer tablet of narrow absorption window drug: Development and in vitro characterisation. Indian J Pharm Sci 2012;74:302-11.

11. Dighe P, Tank HM. design and statistical optimization of a bilayered tablet of metoprolol succinate sustained release and atorvastatin calcium immediate release: Once a day formulation in the management of hypertension. Asian J Pharm Clin Res 2018;11:293-302. 